\title{
Three additional malignancies occurring within one year in a patient with chronic lymphatic leukaemia
}

\author{
M. A. Boots \\ M.B.B.S.
}

G. D. Pegrum

M.D., F.R.C.Path.

\author{
Department of Haematology, Charing Cross Hospital Medical School, \\ St Dunstans Road, London W6 8RF
}

\begin{abstract}
Summary
A patient with chronic lymphatic leukaemia (CLL) is presented who was first seen with a basal cell carcinoma and subsequently developed two further malignant conditions within a year, without receiving any treatment for his leukaemia. It is suggested that this leukaemia was a predisposing factor in the development of his carcinomas.
\end{abstract}

\section{Introduction}

It has been suggested for some years that chronic lymphatic leukaemia predisposes patients to additional malignancies (Manusow and Weinerman, 1975 ) but this might be influenced by other factors such as selection and previous treatment (Moayeri et al., 1976).

The authors consider that leukaemia is often found incidentally when the more urgent malignancy presents. They have recently seen skin tumours (basal cell carcinoma and malignant melanoma) as the initial disease, while in other instances, there have been carcinomas involving lung or intestine. As the disease occurs in the elderly an increased incidence of other malignancies is to be expected but at what level does one begin to believe there is an association? A patient is now described who presented with a basal cell carcinoma, was found to have chronic lymphatic leukaemia and proceeded to develop tumours of both the bladder and the stomach in the space of one year.

\section{Case report}

A 69-year-old retired tailor presented with a basal cell carcinoma on the left side of his nose. His general health was good, the only previous serious illness had been an attack of pleurisy one year before. The carcinoma was excised and no radiotherapy was given. A routine blood count at the time showed haemoglobin $13.5 \mathrm{~g} / \mathrm{dl}$, white cell count $84 \times 10^{9} / 1$, platelet count $124 \times 10^{9} / 1,62 \%$ of the white cells were mature lymphocytes and $30 \%$ of white cells were smear cells. A bone marrow aspiration supported the diagnosis of chronic lymphatic leukaemia (CLL). Lymphocyte studies indicated a ' $B$ ' lymphocyte predominance. The immunoglobulins at the time were IgG $3.2 \mathrm{~g} / 1$ (N 5.2-8.2), IgA 0.95 g/l (N 0.9-3.0), IgM 0.85 g/l ( $\mathrm{N} 0 \cdot 7-2 \cdot 3)$. Close examination revealed only a few small nodes in both axillae but no other abnormal physical signs. At follow-up 7 months later he complained of painless haematuria, and cystoscopy revealed a poorly differentiated, infiltrating, transitional cell carcinoma of the bladder. This was treated with ${ }^{60} \mathrm{Co}(4000 \mathrm{rad})$. The following month he began to feel unwell with weight-loss of $6 \mathrm{~kg}$ and on examination the liver and spleen were palpable, both one finger breadth below the costal margin. His blood count was unchanged and no treatment for his CLL was given.

When admitted for check cystoscopy 5 months after the initial treatment of the bladder carcinoma no residual tumour was present but he complained of continuing weight-loss, increasing girth, anorexia and a 2-week history of vomiting, particularly after meals.

On examination his liver was greatly enlarged to $10 \mathrm{~cm}$ below the costal margin and it contained large, hard, irregular masses which were considered to be metastases. The spleen was just palpable. A few days later he rapidly developed apraxia, became increasingly cachectic and died.

At post-mortem he was found to have a widely disseminated, anaplastic gastric carcinoma with metastatic spread especially to the lungs and liver. There remained a small, shallow malignant ulcer in the bladder. There was evidence of his CLL with generalized enlarged lymph nodes, an enlarged spleen $(353 \mathrm{~g})$ and lymphoid infiltration in the liver. The immediate cause of death was cerebral infarction and bronchopneumonia. 


\section{Discussion}

The finding of an additional malignant condition in elderly patients dying of one cancer is not an uncommon post-mortem finding (Ostrowski, 1975).

The presence of four neoplastic conditions occurring together requires comment, particularly in view of the rapid time course. Five cancers have been reported in two women (Ostrowski, 1975) but they did not have haematological disease. It has been suggested that the more primary neoplasms that develop the greater the risk of developing successive cancers (Moertel, 1966). This might be regarded as a failure of the general immunological defence mechanism in malignant disorders and certainly altered immunity is part of chronic lymphatic leukaemia. This increases the likelihood of further malignancies and this seems to be true especially of skin cancer (Manusow et al., 1975).

Many patients with CLL have been treated, often with chlorambucil and a higher incidence of other malignancies has been demonstrated after this therapy (Manusow et al., 1975). The present patient was not treated with systemic cytotoxic drugs and the irradiation received was only locally to the bladder. His leukaemic process was not particularly aggressive although his IgG was low, but this finding is probably unrelated to further malignancies (Moayeri et al., 1976). The white cell count did not rise terminally and only mild anaemia was present. Despite this, the authors consider that his leukaemia was an important factor in the development of his further malignancies which were found so rapidly after his initial presentation. In this instance, the evidence from one patient is perhaps more compelling than the larger statistical surveys. It is extremely unlikely that chance alone would have provided this sequence of events.

\section{References}

Manusow, D. \& Weinerman, B.H. (1975) Subsequent neoplasia in chronic lymphatic leukaemia. Journal of the American Medical Association, 232, 267.

Maoyeri, H., Tin Han, Stutzman, L. \& Sokal, J.E. (1976) Second neoplasms with chronic lymphatic leukemia. New York State Journal of Medicine, 76, 378.

Moertel, C.G. (1966) Recent Results in Cancer Research, 7, p. 8. Springer Verlag, Berlin.

OstrowsKI, M.J. (1975) Five separate malignancies in one patient all apparently successfully treated. British Medical Journal, 4, 736. 